\title{
Diagnosis and management of folate deficiency in low birthweight infants
}

\author{
M. K. STRELLING, D. G. BLACKLEDGE, AND H. B. GOODALL \\ Department of Paediatrics, Plymouth General Hospital, and Department of Pathology, Ninewells \\ Hospital
}

SUMMARY Significant folate deficiency in 14 out of 37 preterm infants of birthweights $2 \cdot 0 \mathrm{~kg}$ or less was found to be reliably and most conveniently diagnosed by abnormal morphological changes in peripheral blood and confirmed by the response to folic acid. Deficiency appeared to be more common in light-for-dates infants including the smaller of twins. Neither the clinical status nor the levels of haemoglobin or erythrocyte folate was a reliable guide to the presence of megaloblastic erythropoiesis in the very young preterm infant. 100-200 $\mu \mathrm{g}$ folic acid a day, orally or IM, may be required to ensure an optimal haematological response, and this would be appropriate for therapeutic trial if the diagnosis is in doubt. This amount would also replenish tissue folate stores; larger doses are likely to exceed the requirements of small infants.

In an earlier paper (Strelling et al., 1966) we drew attention to the vulnerability of premature infants to folate-responsive megaloblastic anaemia. The most appropriate dose of folic acid for the treatment of affected infants is however unknown. The effect of varying amounts of folic acid on 19 infants is reported, in whom the morphology of the peripheral blood was either frankly megaloblastic or highly suggestive of such change. The diagnosis of folate deficiency in the very young low birthweight infant and the value of a therapeutic trial with small 'physiological' amounts of folic acid are also considered.

\section{Materials and methods}

The infants with observed or suspected megaloblastosis were discovered during the course of an investigation into the folate status of approximately 100 infants between birth and 12 months. 37 of these fulfilled the following criteria: (a) gestation $<37$

Plymouth General Hospital, Devon

M. K. STRELling, consultant paediatrician

Dubbo Base Hospital, Dubbo, New South Wales, Australia D. G. BLACKLEDGE, consultant obstetrician

Ninewells Hospital, Dundee, Angus

H. B. GOODALL, senior lecturer in pathology completed weeks*, (b) birthweight $2.0 \mathrm{~kg}$ or less*, (c) unaffected by a major congenital abnormality or haemolytic disease. They were as far as possible consecutive admissions to a special care baby unit.

24 were term (38-42 completed weeks), normal, singleton infants from uncomplicated 1st or 2nd pregnancies weighing at least $3.0 \mathrm{~kg}$ at birth selected as controls with informed parental cooperation. All these infants thrived.

None of the mothers in either group of infants had been folate-deficient or had received folic acid supplements during pregnancy.

Feeding. The preterm infants were fed evaporated milk (Carnation) changing to full-cream dried milks when their weights had reached $2 \cdot 5 \mathrm{~kg}$. From the 3rd week they were given $22 \mathrm{mg}$ elemental iron in $4 \mathrm{ml}$ sodium iron edetate (Sytron, Parke-Davis) and 7 drops of a multivitamin preparation not containing folic acid (Protovite, Roche) each day. All except 2 control infants who were breast fed received dried milk feeds. The milks were sterilised by autoclaving after reconstitution.

Investigations. Blood was taken by heel prick just after birth, repeated at 2 to 4 weeks, and at least twice during weeks 5 to 10 . Further samples were

* One infant of 37 weeks and one of birthweight $2.06 \mathrm{~kg}$ with suspected megaloblastosis were included. 
taken during weeks 11 to 20 and between months 6 and 12. The following examinations were made: $\mathrm{Hb}, \mathrm{MCHC}$, reticulocytes, PCV, and films. Buffy coat smears were taken from microhaematocrit preparations spun relatively slowly $(750 \mathrm{rev} / \mathrm{min})$ for 5 minutes.

Assays of whole-blood folate ( $L$. casei) were made on duplicate samples of $50 \mu$ l blood using the method described previously (Strelling et al., 1966), red-cell folate being calculated from the haematocrit.

Abnormal haemopoiesis was assessed on blood and buffy coat smears as: (1) megaloblastic; the presence of megaloblasts or transitional megaloblasts with eosinophilic or polychromatophilic cytoplasm, or (2) suspected megaloblastic; orthochromatic oval macrocytes, macronormoblasts, and hypersegmented neutrophils. Marrow biopsies were not taken.

Folic acid treatment. Folic acid was given daily as follows: (1) $5 \mathrm{mg} \mathrm{IM} \mathrm{(6} \mathrm{infants)} \mathrm{and} \mathrm{orally} \mathrm{(1} \mathrm{infant),}$ (2) 1-2 mg orally (4 infants), (3) $60 \mu \mathrm{g}$ IM (2 infants) or $50 \mu \mathrm{g}$ orally ( 2 infants), and (4) $15-120 \mu \mathrm{g}$ IM initially, the amount being increased every few days depending on the haematological response (4 infants).

As only $5 \mathrm{mg}$ tablets of folic acid were available both $1 \mathrm{mg}$ and $50 \mu \mathrm{g}$ tablets of folic acid were prepared commercially. A parenteral folic acid solution containing $15 \mathrm{mg} / \mathrm{ml}$ (Folvite, Lederle) was appropriately diluted immediately before each IM injection.

The haemopoietic response was assessed on the reticulocyte count, blood films, and buffy coat smears.

Birthweight/gestation centiles. These are from the data of (1) Thomson et al. (1968) for infants born after 31 completed weeks, allowing for sex and parity, (2) Babson et al. (1970) for infants born between 28 and 31 completed weeks.

\section{Results}

Findings in low birthweight infants. Megaloblastosis was observed in 19 of the preterm infants with birthweights of $2 \mathrm{~kg}$ or less. Data on these infants are shown in Table 1 . In 14 the diagnosis was confirmed by the haematological response to treatment with folic acid, but this was suboptimal in 4 (Cases 15-18) and was not assessed in one (Case 19). The remaining 18 low birthweight infants showed no morphological evidence of folate deficiency, and none of the 6 who received a trial of folic acid showed any haematological effect. Data on these infants and the controls are shown in Table 2.
Nine ( $64 \%$ ) of the confirmed megaloblastic group had birthweights below the 10th centile compared with $5(28 \%)$ of the normoblastic group. In all the 45 infants who were below 37 weeks' gestation irrespective of birthweight, there were significantly more who were light-for-dates in the megaloblastic group $(P<0 \cdot 05)$.

$\mathrm{Hb}$ was invariably below $10 \mathrm{~g} / \mathrm{dl}$ in the megaloblastic infants at diagnosis but it was also at this level in 13 of the 18 normoblastic infants. The mean difference in $\mathrm{Hb}$ at average age 7 weeks was $1 \cdot 1$ $\mathrm{g} / \mathrm{dl}$, values in the megaloblastic group being significantly lower $(P<0 \cdot 05$, Table 2$)$.

Erythrocyte folate levels in 22 of the 37 low birthweight infants at average age 7 weeks were below those in controls of comparable postnatal age $(P<0.05$, Table 2). Values in 3 infants with confirmed or suspected megaloblastosis and in 5 of the normoblastic low birthweight group were nevertheless within the control range.

None of the control infants at any time and no low birthweight infant over 12 weeks showed any cytological evidence of folate deficiency on peripheral blood examination. Three of the normoblastic low birthweight infants who did not receive folic acid had erythrocyte folate levels $<100 \mu \mathrm{g} / \mathrm{l}$ at 6 months.

The condition of no infant caused undue concern when morphological evidence of folate deficiency was found, although in 4 there had been previous clinically mild infections of the urinary or respiratory tracts.

Serum vitamin B12 values (Lactobacillus leichmanni) in 5 low birthweight infants were 150-335 $\mathrm{ng} / \mathrm{l}$ (normal 160-950 ng/l).

\section{Treatment with folic acid.}

\section{Standard doses (1-5 mg daily)}

An unequivocal response occurred in all 6 infants given $5 \mathrm{mg}$ folic acid daily IM (Cases 1-6) and in 3 of the 4 given 1 or $2 \mathrm{mg}$ orally (Cases 7-9). Blood films and buffy coat smears examined between days 3 and 7 showed normoblastic transformation and a pronounced increase in polychromatophilic erythrocytes. Reticulocytes were often slightly increased before treatment but a definite subsequent rise was nevertheless demonstrable. Enlargement of spleen and/or liver was noted in several infants after treatment with folic acid; the reason for this was not clear.

The haematological response was suboptimal in Case 15 ( $5 \mathrm{mg} /$ day orally) and was not assessed in Case 19 ( $2 \mathrm{mg} /$ day orally).

Whole-blood folate was estimated in 4 megaloblastic infants receiving $5 \mathrm{mg} /$ day folic acid IM and 

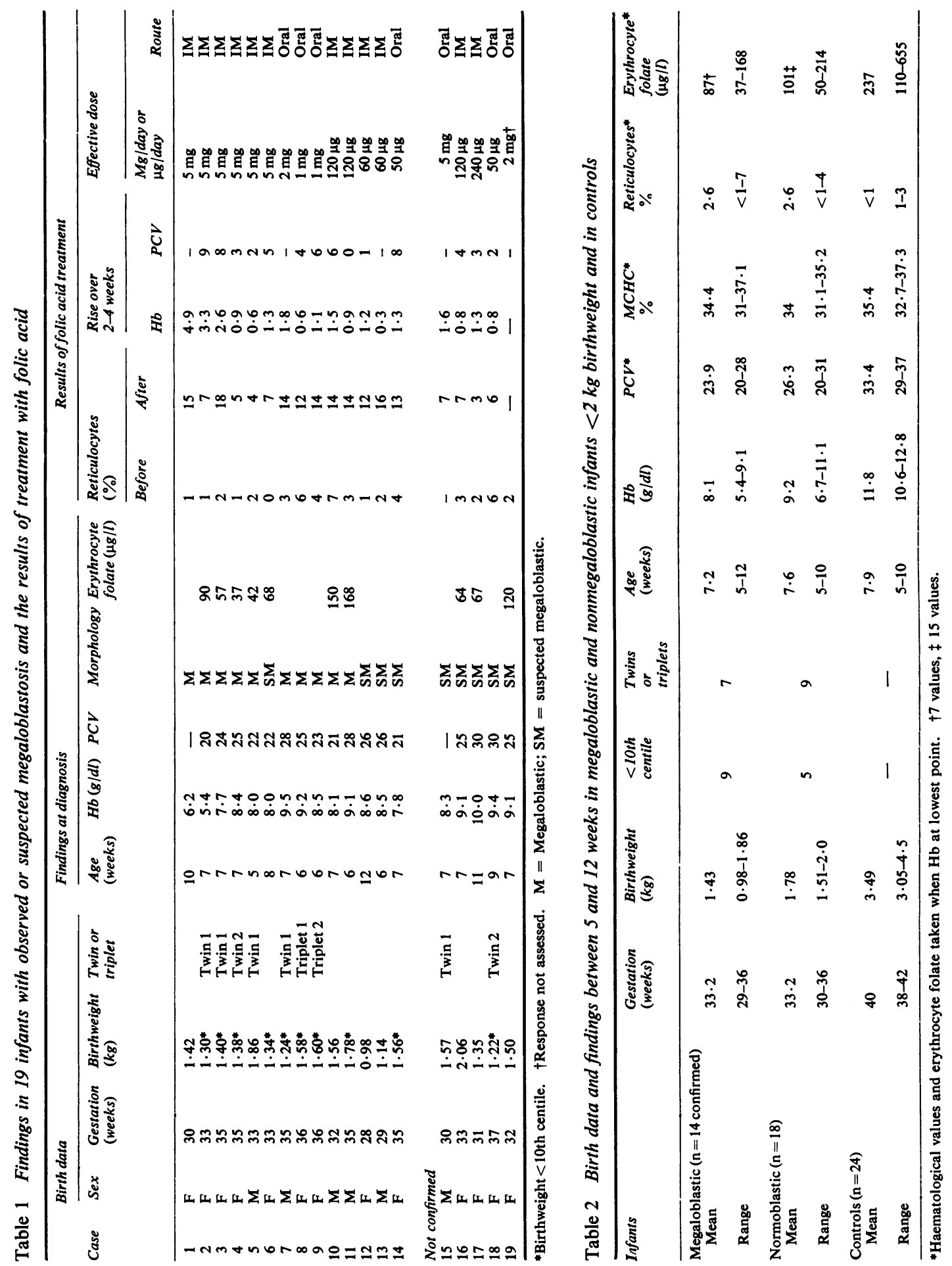
in 12 further infants of birthweights $2 \cdot 0-3 \cdot 0 \mathrm{~kg}$ receiving 5 or $10 \mathrm{mg} /$ day orally. Values $>1000 \mu \mathrm{g} / \mathrm{l}$ were invariably found. These were not assayed precisely in this high range but would almost certainly have produced red-cell folate values well above normal. Erythrocyte folate assayed after stopping treatment declined slowly; at an average age of 7 weeks later the mean value in 11 infants was $828 \mu \mathrm{g} / 1(405-1406 \mu \mathrm{g} / \mathrm{l})$.

\section{Unchanging small doses}

Both infants given $60 \mu \mathrm{g} /$ day of folic acid IM (Cases 12 and 13) and one of the 2 given $50 \mu \mathrm{g} /$ day orally (Case 14) showed a brisk normoblastic and reticulocyte response; erythrocyte folate was not measured. The response to $50 \mu \mathrm{g} / \mathrm{day}$ of folic acid orally in the 4th infant (Case 18) was difficult to assess as the abnormal morphology had improved spontaneously in the week before treatment when the reticulocytes were $6 \%$.

\section{Increasing small doses}

In an attempt to find a minimum effective therapeutic dose, 4 infants were given progressive increments of folic acid while the morphology and red-cell folate were monitored. Details are given below.

\section{Case reports}

Case 10 (Figure). A baby boy, birthweight $1.56 \mathrm{~kg}$, 32 weeks' gestation. At 7 weeks $\mathrm{Hb} 8 \cdot 1 \mathrm{~g} / \mathrm{dl}$, PCV 22, and erythrocyte folate $150 \mu \mathrm{g} / \mathrm{l}$. Transitional megaloblasts were noted in buffy coat smears and, 2 days later, true megaloblasts. The reticulocytes had begun to rise $(7 \%)$ before folic acid was started.

$15 \mu \mathrm{g}$ folic acid IM for 3 days and $60 \mu \mathrm{g}$ IM for 2 days produced no haematological response and megaloblasts persisted. Two doses of $120 \mu \mathrm{g} /$ day IM were followed by an increase in polychromatic erythrocytes, and these and normoblasts were smaller. Megaloblasts disappeared and reticulocytes rose to $10 \%$ although the erythrocyte folate fell slightly to $122 \mu \mathrm{g} / \mathrm{l}$. This response continued for a further 7 days with a peak reticulocytosis of $14 \%$ after $10 \times 120 \mu \mathrm{g}$ folic acid IM when the erythrocyte folate was $\mathbf{5 3 0}$ $\mu \mathrm{g} / \mathrm{l}$. The intensity of response then diminished gradually despite increased dosage.

\section{Comment}

A haematological response and a rise in erythrocyte folate was obtained with $120 \mu \mathrm{g} /$ day folic acid IM.

Case 11. A baby boy, birthweight $1.78 \mathrm{~kg}(<10$ th centile), gestation 35 weeks. At 6 weeks $\mathrm{Hb} \mathrm{9 \cdot 1} \mathrm{g} / \mathrm{dl}$, PCV 28, reticulocytes $3 \%$. Transitional megaloblasts and slightly increased polychromasia on blood films.

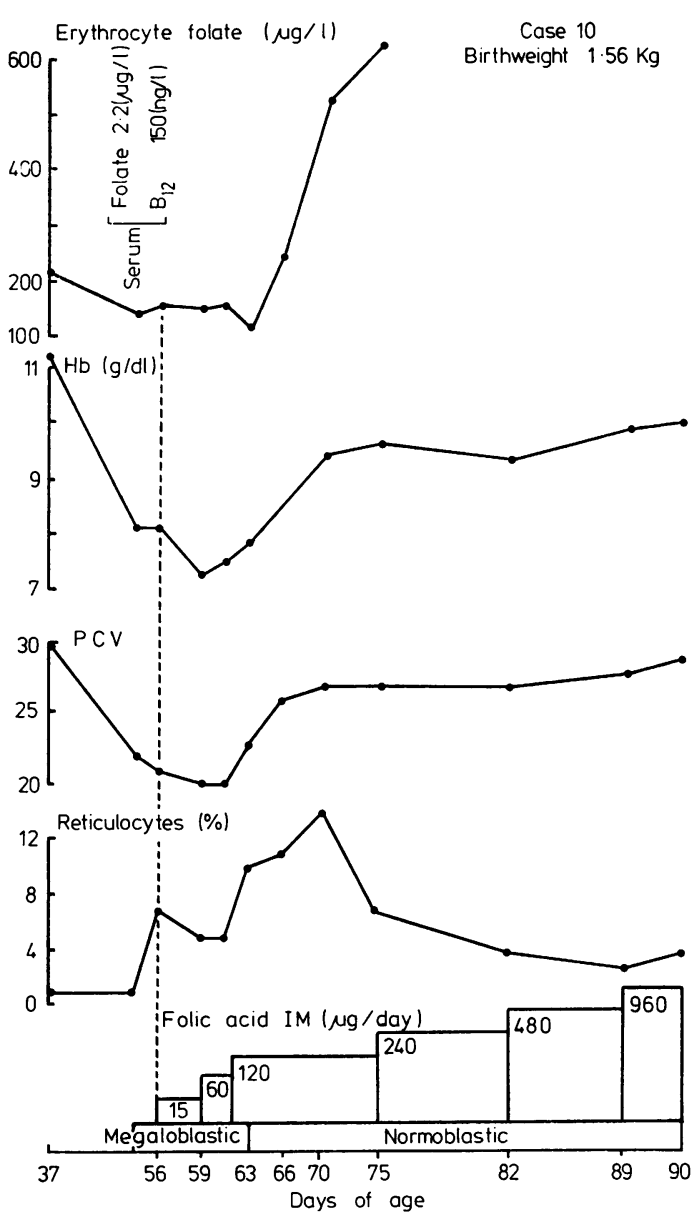

Figure Treatment of megaloblastic anaemia in a preterm infant with increasing small doses of folic acid.

Erythrocyte folate $168 \mu \mathrm{g} / \mathrm{l}$. Folic acid $60 \mu \mathrm{g} /$ day IM produced a moderate normoblastic response with reticulocytes of $5 \%$ on day 2 rising to $14 \%$ on day 7.

Erythrocyte folate was $167 \mu \mathrm{g} / 1$ on day 6 but fell to $108 \mu \mathrm{g} / \mathrm{l}$ on day 15 so the folic acid was increased to $120 \mu \mathrm{g} /$ day IM. The reticulocytes remained raised until 6 weeks after beginning treatment.

\section{Comment}

Although a good haematological response occurred on $60 \mu \mathrm{g} / \mathrm{day}$ folic acid IM the erythrocyte folate declined; $120 \mu \mathrm{g} /$ day might have been the appropriate dose.

Case 16. A baby girl, birthweight $2.06 \mathrm{~kg}$, gestation 33 weeks. At 7 weeks folate deficiency was suspected, 
Hb $9 \cdot 1 \mathrm{~g} / \mathrm{dl}$, PCV 25 , reticulocytes $3 \%$. Erythrocyte folate was low at $64 \mu \mathrm{g} / \mathrm{l}$. A week later the morphology was less abnormal, $\mathrm{Hb} 9.9 \mathrm{~g} / \mathrm{dl}$, reticulocytes $5 \%$, and erythrocyie folate $88 \mu \mathrm{g} / \mathrm{l}$. Folic acid 60 $\mu \mathrm{g} /$ day was given IM and although polychromatic cells and reticulocytes increased slightly $(7 \%)$, the response was not definite. As the erythrocyte folate had fallen to $40 \mu \mathrm{g} / 1$ on day 7 , folic acid was increased to $120 \mu \mathrm{g} /$ day IM.

Case 17. A baby girl, birthweight $1 \cdot 35 \mathrm{~kg}$, gestation 31 weeks. At 11 weeks folate deficiency was suspected on blood films which showed pronounced neutrophil hypersegmentation. $\mathrm{Hb} 10 \mathrm{~g} / \mathrm{dl}, \mathrm{PCV} 30$, reticulocytes $2 \%$. Erythrocyte folate was low at $67 \mu \mathrm{g} / \mathrm{l}$. A week later without treatment the morphology was less abnormal, $\mathrm{Hb} 9.6 \mathrm{~g} / \mathrm{dl}, \mathrm{PCV} 27$, reticulocytes $4 \%$. Erythrocyte folate had risen to $140 \mu \mathrm{g} / \mathrm{l}$. There was a slight haematological response after 3 days of treatment with folic acid $120 \mu \mathrm{g} /$ day IM. As the erythrocyte folate had fallen to $86 \mu \mathrm{g} / 1$ the dose was increased to $240 \mu \mathrm{g} /$ day IM for a further 3 days.

\section{Comment}

Morphological abnormalities improved in Cases 16 and 17 before treatment. The haematological response to $60 \mu \mathrm{g} /$ day IM (Case 16) or to $120 \mu \mathrm{g} /$ day IM (Case 17) was suboptimal. Erythrocyte folate fell in both infants, suggesting these amounts fell short of requirements.

\section{Discussion}

Diagnosis. Megaloblastic haemopoiesis may be overlooked in small infants. Clinical pointers to severe folate insufficiency which might have been expected-such as pallor, poor feeding, slow weight gain (Gandy and Jacobson, 1977), or severe infections (Gray and Butler, 1965) -were generally absent when the diagnosis was made and earlier infections in a minority of infants had been clinically mild. Neither $\mathrm{Hb}$ nor erythrocyte folate level was found to be a reliable guide to megaloblastic haemopoiesis. No affected infant had $\mathrm{Hb}>10 \mathrm{~g} / \mathrm{dl}$ but only a few were significantly anaemic for infants of comparable birthweights and ages (Lundstrom et al., 1977). Megaloblastosis however developed at an average age of 7 weeks when the effect of folate deficiency on $\mathrm{Hb}$ level is likely to be masked by such major physiological variables as red-cell mass at birth, postnatal depression of erythropoiesis, and rate of growth. The erythrocyte folate often fell during the 2 nd and 3rd months to subnormal levels in both normoblastic and megaloblastic infants $<2 \mathrm{~kg}$ birthweight, but values did not necessarily reflect the true severity of folate depletion. These were within the range found in term healthy controls $(110-655 \mu \mathrm{g} / \mathrm{l})$ in 2 infants with confirmed and one with suspected megaloblastosis, presumably due to the survival of erythrocytes formed during the perinatal period of relative folate affluence.

On the other hand, a clinical feature not previously described is a possible relationship between low birthweight for gestational age and the subsequent development of megaloblastic anaemia, for there was an undue proportion of preterm infants who were light-for-dates $(<10$ th centile) among the megaloblastic group. Moreover, in 2 twin pregnancies only the smaller of each pair was affected. The reason for this is uncertain: limited fetal acquisition of folate or relatively rapid postnatal growth (Gairdner and Pearson, 1971) may well be contributory factors. An association between erythroblastosis, rate of weight gain, and folate insufficiency in infants up to one year has been reported (Gandy and Jacobson, 1977). While we were unable to find megaloblastic haemopoiesis in a group of erythroblastotic infants studied from birth, there was a haematological response after folic acid treatment in 2 affected preterm infants who had become severely anaemic at 3 and 5 weeks (Strelling, 1977).

The mainstay of diagnosis of folate deficiency was abnormal morphology using the buffy layer of capillary blood centrifuged slowly to concentrate abnormal cells, particularly the megaloblasts. While morphological abnormalities were sometimes shortlived and were not found in any case beyond 12 weeks, a search for them appears essential to the evaluation of the folate status of very young preterm infants.

Prevention. Whether folate insufficiency affects the somatic growth or neurological development of preterm infants is unknown. Lack of the vitamin limits the synthesis of thymidylate, a necessary precursor of DNA, megaloblastosis representing a stage at which DNA replication has become deranged (Hoffbrand et al., 1976). Deficiency not severe enough to produce megaloblastosis may nevertheless impair growth, as shown in erythroblastotic infants by Gandy and Jacobson (1977). Dallman (1974a) estimated that preterm infants need 50-70 $\mu \mathrm{g}$ $(25-35 \mu \mathrm{g} / 100 \mathrm{kcal})$ of folate a day. Neither the newer ready-to-feed proprietary milks $(3 \cdot 2-3 \cdot 5 \mu \mathrm{g} / 100$ $\mathrm{ml}^{*}$ ) nor fresh human milk (average $5.4 \mu \mathrm{g} / 100 \mathrm{ml}$, Ford and Scott, 1968) is likely to supply more than $10-20 \mu \mathrm{g} /$ day of folate to very low weight infants over the first 8 weeks. Evaporated milk given to the infants in this study may have provided even less, for such milk with a relatively small ascorbic acid

*Manufacturers' reports. 
content tends to lose heat-labile folate through sterilisation (Ford and Scott, 1968). As preterm infants are vulnerable to deficiency during a period of rapid growth and cell replication, we would continue to advocate that folic acid supplements of about $50 \mu \mathrm{g} /$ day be given to those under $2 \mathrm{~kg}$ for the first 3 months to ensure an ample supply for growth and development.

Treatment. There is little information on the optimal amount of folic acid required for the treatment of preterm infants with megaloblastic anaemia. Recommended doses generally vary between $500 \mu \mathrm{g}$ (Dallman, 1974b) and 2-5 mg (Smith, 1972; Pearson, 1975) a day, although Willoughby (1977) suggests that $200 \mu \mathrm{g}$ may be enough in uncomplicated cases.

We found that 5 or $10 \mathrm{mg} /$ day folic acid either orally or IM produced high blood folate levels and was clearly in excess of the requirements of small infants; an oral dose of 1 or $2 \mathrm{mg}$ gave an equally good haematological response.

Daily doses of between $50 \mu \mathrm{g}$ orally and $120 \mu \mathrm{g}$ IM also produced an optimal haematological response in 5 out of 8 infants tested. The response to the same dose in the other 3 was suboptimal, possibly because morphological abnormalities had improved and reticulocytes begun to rise before treatment was started.

Erythrocyte folate was monitored in 4 of the 8 infants given small doses of folic acid. $60 \mu \mathrm{g} /$ day IM was accompanied by falling levels in 3 infants, in one of whom increasing the amount to $120 \mu \mathrm{g}$ produced a satisfactory rise. The same dose was associated with a drop in folate in the 4th infant.

Hence, although an excellent haematological response may follow as little as $50 \mu \mathrm{g} /$ day folic acid, this amount is unlikely to meet the demands of increased haemopoiesis and, at the same time, replenish the infant's stores of folate. Needs may also vary and a full haemopoietic response may not always occur on this amount. Therefore the optimal therapeutic dose of folic acid is probably in the region of $100-200 \mu \mathrm{g} /$ day orally or IM. Crystalline folic acid (pteroylmonoglutamic acid) was well absorbed orally in the small infants but suitable small dose oral or parenteral preparations are not readily available in the UK.

It may be considered whether treatment with excess folic acid could be potentially harmful, especially to the immature brain. Although folic acid has potent convulsive effects in experimental animals when injected directly into CSF or the brain (Hommes and Obbens, 1972) there appears to be an efficient homeostatic mechanism in the blood-brain barrier which helps maintain CSF and probably brain levels of folate within relatively narrow limits
(Spector and Lorenzo, 1975). The main objection to the use of excess folic acid appears to be if vitamin B12 deficiency were present. A suboptimal haematological response may then follow treatment with large doses of folic acid and there is at least a theoretical risk that such treatment may precipitate central nervous system damage. Thus brain damage associated with congenital vitamin B12 deficiency has been reported (Pearson et al., 1964; McNicholl and Egan, 1968); 4 of these infants with congenital deficiency of intrinsic factor had been treated with large amounts of folic acid (Strelling, 1969). There is insufficient information concerning the vitamin B12 status of preterm infants. 14 out of 24 such infants in one report (Pathak and Godwin, 1972) had subnormal serum levels although values in 5 low weight infants in this study were in the low normal range.

It may be concluded that significant folate deficiency in infants $<2 \mathrm{~kg}$ birthweight may be reliably and most conveniently diagnosed on abnormal morphological changes in peripheral blood and adequately treated with $100-200 \mu \mathrm{g} /$ day folic acid, orally or IM. The haematological response to this amount would also serve as a therapeutic trial when the diagnosis is in doubt.

We thank Professor J. R. Ashford, Department of Mathematics, Exeter University, and Professor J. R. T. Colley, Department of Community Health, Bristol University for help with statistical analyses, and Wyeth Laboratories for financial support.

\section{References}

Babson, S. G., Behrman, R. E., and Lessel, R. (1970). Fetal growth: liveborn birth weights for gestational age of white middle class infants. Pediatrics, 45, 937-944.

Dallman, P. R. (1974a). Iron, vitamin E, and folate in the pre-term infant. Journal of Pediatrics, 85, 742-752.

Dallman, P. R. (1974b). The nutritional anaemias. In Hematology of Infancy and Childhood, p. 130. Edited by D. G. Nathan and F. A. Oski. Saunders: Philadelphia.

Ford, J. E., and Scott, K. J. (1968). The folic acid activity of some milk foods for babies. Journal of Dairy Research, 35, 85-89.

Gairdner, D., and Pearson, J. (1971). A growth chart for premature and other infants. Archives of Disease in Childhood, 46, 783-787.

Gandy, G., and Jacobson, W. (1977). Influence of folic acid on birthweight and growth of the erythroblastotic infant. II. Growth during the first year. Archives of Disease in Childhood, 52, 7-15.

Gray, O. P., and Butler, E. B. (1965). Megaloblastic anaemia in premature infants. Archives of Disease in Childhood, 40, 53-56.

Hoffbrand, A. V., Ganeshaguru, K., Hooton, J. W. L., and Tripp, E. (1976). Megaloblastic anaemia. Clinics in Haematology, 5, 727-745.

Hommes, O. R., and Obbens, E. A. M. T. (1972). The 
epileptogenic action of $\mathrm{Na}$-folate in the rat. Journal of the Neurological Sciences, 16, 271-281.

Lundström, U., Siimes, M. A., and Dallman, P. R. (1977). At what age does iron supplementation become necessary in low-birthweight infants. Journal of Pediatrics, 91, 878-883.

McNicholl, B., and Egan, B. (1968). Congenital pernicious anemia: effects on growth, brain, and absorption of $\mathbf{B}_{12}$. Pediatrics, 42, 149-156.

Pathak, A., and Godwin, H. A. (1972). Vitamin $\mathbf{B}_{12}$ and folic acid values in premature infants. Pediatrics, 50, 584-589.

Pearson, H. A. (1975). Megaloblastic anemias. In Nelson Textbook of Pediatrics, p. 1115. Edited by V. C. Vaughan and R. J. McKay. Saunders: Philadelphia.

Pearson, H. A., Vinson, R., and Smith, R. T. (1964). Pernicious anemia with neurologic involvement in childhood. Journal of Pediatrics, 65, 334-339.

Smith, C. H. (1972). Blood Diseases of Infancy and Childhood, p. 248. Mosby: St Louis.

Spector, R., and Lorenzo, A. V. (1975). Folate transport in the central nervous system. American Journal of Physiology, 229, 777-782.
Strelling, M. K. (1969). Brain damage from congenital pernicious anaemia. Developmental Medicine and Child Neurology, 11, 378-380.

Strelling, M. K. (1977). Letter: Folic acid levels in erythroblastotic infants. Archives of Disease in Childhood, 52, 668-669.

Strelling, M. K., Blackledge, G. D., Goodall, H. B., and Walker, C. H. M. (1966). Megaloblastic anaemia and whole-blood folate levels in premature infants. Lancet, 1 , 898-900.

Thomson, A. M., Billewicz, W. Z., and Hytten, F. E. (1968). The assessment of fetal growth. Journal of Obstetrics and Gynaecology of the British Commonwealth, 75, 903-916.

Willoughby, M. L. N. (1977). Paediatric Haematology, p. 29. Churchill Livingstone: Edinburgh.

Correspondence to Dr M. K. Strelling, Department of Paediatrics, Plymouth General Hospital, Plymouth, Devon.

Received 15 September 1978 